\title{
CEO INCENTIVES AND FIRM SIZE
}

\author{
George P. Baker \\ Brian J. Hall
}

\author{
Working Paper 6868 \\ http://www.nber.org/papers/w6868
NATIONAL BUREAU OF ECONOMIC RESEARCH
1050 Massachusetts Avenue
Cambridge, MA 02138
December 1998

We thank Ashish Nanda, Nancy Rose, and participants at the Fain Conference on Agency, RiskBearing and Incentives at Firms, held at Brown University in October 1998 for helpful comments. We also thank Jia Liu and Ali Ahsan for excellent research assistance. The views expressed here are those of the author and do not reflect those of the National Bureau of Economic Research.

( 1998 by George P. Baker and Brian J. Hall. All rights reserved. Short sections of text, not to exceed two paragraphs, may be quoted without explicit permission provided that full credit, including ${ }^{(}$notice, is given to the source. 
CEO Incentives and Firm Size

George P. Baker and Brian J. Hall

NBER Working Paper No. 6868

December 1998

\section{ABSTRACT}

What determines CEO incentives? A confusion exists among both academics and practitioners about how to measure the strength of CEO incentives, and how to reconcile the enormous differences in pay sensitivities between executives in large and small firms. We show that while one measure of CEO incentives (the dollar change in CEO wealth per dollar change in firm value) falls by a factor of ten between firms in the smallest and largest deciles in our sample, another measure of CEO incentives (the value of CEO equity stakes) increases by roughly the same magnitude. We resolve the confusion about which of these measures better reflects $\mathrm{CEO}$ incentives by developing and solving a model that allows $\mathrm{CEO}$ productivity to differ for firms of different sizes. The crucial parameter is shown to be the elasticity of CEO productivity with respect to firm size. Our empirical results suggest that CEO marginal products rise significantly, and overall CEO incentives are roughly constant or decline slightly with firm size. We also show that the appropriate measure of incentives depends on the type of CEO activity being considered. For activities whose dollar impact is the same for large and small firms (such as the purchase of a corporate jet), the dollars-on-dollars measure is appropriate, and large firms suffer significant agency problems due to their weak incentives. For activities whose percentage impact is similar across firms of different sizes (such as a corporate reorganization) the equity stake measure is better, and the incentive problem faced by large firms is not as severe. Finally, using a multi-task model, we discuss the implication of our findings for the design of control systems.

George P. Baker

Harvard Business School

Baker Library 283

Boston, MA 02163

and NBER

gbaker@hbs.edu
Brian J. Hall

Harvard Business School

Baker Library 284

Boston, MA 02163

and NBER

bhall@hbs.edu 


\section{Introduction}

How do the incentives for large firm CEOs compare to those of small firm CEOs? A quick glance at Figure 1 below suggests an answer: median pay-to-performance sensitivities (as measured by dollar change in CEO wealth per dollar change in firm value) fall by a factor of 10 in moving from the smallest decile firms to the largest. ${ }^{1}$ What is the implication of this large decline in pay sensitivity? The standard agency model would suggest that

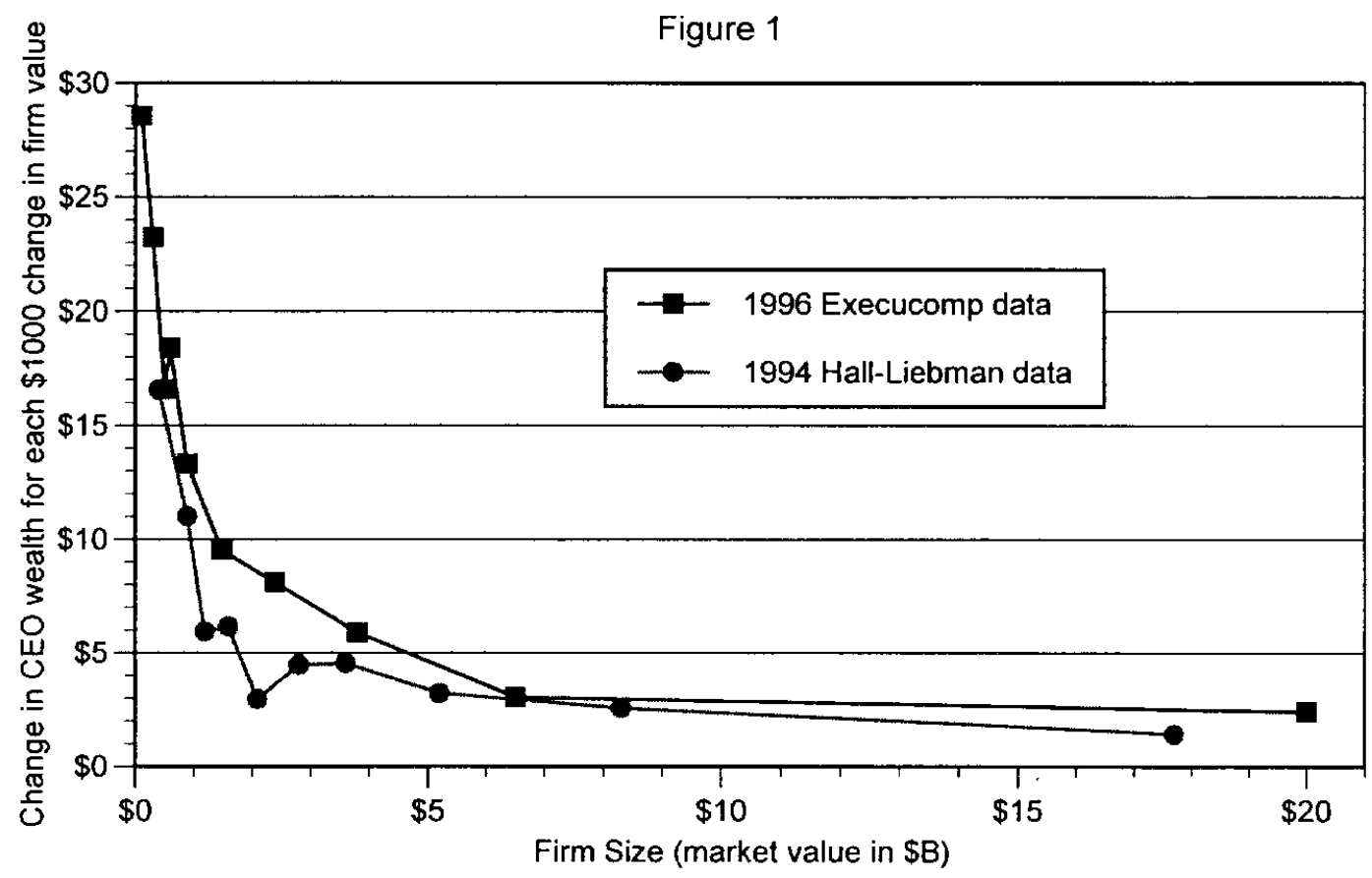

Note: Medians for each size decile are plotted.

incentives fall by a factor of ten! Should we infer from this that the CEOs of large firms work one-tenth as hard as those of small firms? Or that the boards of large firms are significantly more vigilant monitors of the actions of their CEOs than are the boards of small firms? Both of these implications seem at odds with logic and casual empiricism.

1 Several authors, notably Schaefer (1998), have documented the negative relationship between pay sensitivity and firm size. If smaller, non-publicly-traded companies were added to the sample, the difference in sensitivities between the the largest and smallest companies would be between two and three orders of magnitude, since the managers of the smallest companies are often majority shareholders. 
A confused and confusing debate rages among academics, practitioners, and students about what determines CEO incentives. ${ }^{2}$ This confusion manifests itself in a number of ways: in the range of empirical specifications for pay-to-performance regressions in the literature; in the wide discrepancy in estimates of pay sensitivities; in popular controversy over the appropriate level of executive holdings of stock and stock options.

At the heart of this confusion is the problem, noted by Rosen (1992) and Holmstrom (1992), of how to compare the incentives faced by the CEOs of companies of dramatically different sizes. In particular, the notion that CEOs of large companies have trivial incentives relative to CEOs of small companies seems odd given the very large value of the shares and options held by the CEOs of large companies (Hall and Liebman, 1998). Consider that the CEO of a $\$ 100 \mathrm{~B}$ firm, who owns only 0.1 percent of the firm's stock, still holds an equity stake worth $\$ 100 \mathrm{M}$. Given these large stakes, it seems implausible to many that the incentives of large company CEOs are so much weaker than those of small company CEOs. The large equity stake of the large company CEO would seem to give strong incentives to raise the share price, since a small percentage change in the stock price changes the CEO's wealth by millions of dollars. Indeed, it seems plausible that the incentives of this large company-CEO are stronger, rather than weaker, than the incentives facing the small company CEO. This raises the obvious question, which is central to this paper: in terms of the strength of CEO incentives, what matters? Is it only the "percent owned," as the standard model suggests? Or do "dollars at stake" also matter?

This paper attempts to answer several questions about the appropriate measure of incentives for top managers. We develop a model of pay-to-performance sensitivity that bridges the gap between these two "measures" of incentives and enables us to analyze how the strength of incentives relates to the scale of the firm. We use this model to re-examine the data on CEO pay-to-performance relationships, deriving new insights on how variation in firm size affects CEO incentives, firm structure and control systems.

Our model predicts how the optimal pay-to-performance sensitivity of a CEO varies with firm size. As with the standard model, the optimal sensitivity depends on the variability of firm returns, CEO risk aversion and the marginal product of the CEO's actions on firm value. The key difference between our model and the standard one is that we do not

2 See, for example, Jensen and Murphy (1990), Garen (1994), Haubrich (1994), Joskow and Rose (1994), Hall and Liebman (1998), Murphy (1998), Aggarwal and Samwick (1998). 
assume that this latter parameter $-\gamma$, the marginal product of $\mathrm{CEO}$ actions on firm value - is invariant to firm size. Indeed, we argue that the assumption that the marginal product of effort is invariant is one of two polar cases, the other polar case being that CEO marginal product scales proportionally with firm size.

We show that if the marginal product of effort is constant across firm size, then incentives are determined solely by the dollar change in CEO wealth per dollar change in firm value. This measure, which we label " $b$ ", and which we will refer to throughout the paper as "percent owned," 3 falls very quickly as firm size rises (since the variance of firm value explodes with firm size), leaving CEOs of large firms with trivial incentives relative to small-firm CEOs. Although this is the standard model, it is appropriate for thinking only about the class of decisions made by CEOs whose marginal products do not scale with firm size. An example would be the purchase of corporate jets. A CEO that owns 1 percent of the firm can buy a corporate jet at a 99 percent discount and a CEO that owns 10 percent of the firm can buy the jet at a 90 percent discount. This discount to the CEO is invariant to firm size. Only the percent owned matters.

The opposite polar case is when the marginal product of effort scales proportionately with firm size. Examples of actions that scale with firm size might be a corporate reorganization or a change in the strategic focus of the firm. In cases such as these, good (or bad) actions by the CEO affect the entire firm. In the words of Rosen (1992), the CEO's actions have a "chain-letter like" effect on the value firm. We show that in the polar case of proportional scaling (the elasticity of $\gamma$ with respect to firm size is one), the strength of incentives can be inferred from the CEO's equity stake in the firm, $b$ times the value of the firm. ${ }^{4}$ The intuition for this is straightforward: if the marginal product of actions scale proportionally with firm size, then CEO actions affect the percent change, not the dollar change, in firm

3 If the CEO owns only stock, then $b$ is equal to percentage ownership. If the CEO also owns stock options or has pay that is sensitive to firm value, then $b$ will be larger than percent ownership. In this paper, we ignore the sensitivity of annual salary and bonus changes to performance, but we are careful to include the incentive effects of executive stock options. Since, for a given change in stock price. the value of one dollar's worth of stock option changes more than the value of one dollar's worth of stock, $b$ is larger than the CEO's equity stake in the firm (the value of stock and options) divided by firm value.

$4 \quad$ Again, if the CEO owns only stock, then the value of the CEO's stake equals b times firm value. However, since virtually all of our CEO's hold options, the value of their stock and option holdings is less than $b$ times firm value. Throughout the paper, we refer to b times firm value as the CEO's stake in the firm. 
value. In this case, the strength of CEO incentives can be measured by the CEO's equity stake in the firm (which will be multiplied by any percentage point change in firm value.)

We do not consider one other possible variable that might affect the strength of CEO incentives: the fraction of the CEO's wealth that is tied up in the firm. We ignore this variable for two reasons. First, we have no way to measure, with the data available, the non-firm wealth of the CEOs in our sample. But we consider this lack of data to be only a modest drawback, for the following reason. Almost all of the CEOs in our sample have stakes worth millions of dollars; and we do not believe that very many of our CEOs have enough non-firm wealth that it greatly changes their incentives. Is the marginal value of a dollar very different for a CEO whose $\$ 10 \mathrm{M}$ stake represents $90 \%$ of his wealth than for a CEOs whose $\$ 10 \mathrm{M}$ stake represents only $40 \%$ of his wealth? We argue that any crosssectional differences in the marginal utility of income between CEOs with different wealth levels will not be significant when compared to the variations in incentives that come from either their percentage ownership or the size of their stakes. ${ }^{5}$

We use our model, a range of assumptions about CEO risk aversion, and several datasets on CEO pay and equity ownership to estimate the relationship between the marginal product of effort $(\gamma)$ and firm size. The data strongly rejects either of the two polar cases. We find an elasticity of CEO marginal product with respect to firm size that is approximately 0.4 , rejecting an elasticity of zero ( $\gamma$ is constant across firm size) and one $(\gamma$ increases proportionately with firm size). We interpret this as evidence that CEOs do a range of activities, the marginal product of which scales with size in varying degrees.

With regard to total incentives and size, we find that incentives are roughly constant or fall slightly as firms become larger. This is because total incentives-the marginal returns to effort-equals b times $\gamma$. As firms become larger, $b$ falls strongly and $\gamma$ rises sharply. The combined affect in most of our estimates is zero or a small decline. Thus incentives may fall as firm size increases, but not nearly as drastically as the standard model predicts. The large dollar equity stakes of large company CEOs do matter.

Our results have a number of related implications, which we summarize here and detail in Section V.

\footnotetext{
5 We do believe that this variation in the fraction of wealth at stake may change a CEO's propensity to take risks. Analysis of this effect is beyond the scope of this paper.
} 
- We argue that both the empirical and theoretical literatures have mischaracterized the relationship between firm size and managerial marginal products, and as a result provided misleading estimates of pay sensitivity.

- We explain the existence of expensive corporate staffs in large firms as the response to the high marginal product of CEO effort in these firms.

- The low (but optimal) b's in large firms relative to those in smaller firms induce greater agency problems for some activities than others. More specifically, activities whose dollar impact (positive or negative) on large and small firms is the same will create greater agency problems for large firms, necessitating more monitoring by large firms than small.

- We explain the existence of bureaucratic "red tape" in large firms.

The paper proceeds as follows. In the next section, we lay out our model of managerial production and compensation, including our strategy for estimating the marginal product of CEO effort. In Section III, we describe our data sources and summarize the data. Section IV contains our estimates of the elasticity of CEO marginal products with respect to firm size, and our estimates of incentive differences across firms of different sizes. Section $\mathrm{V}$ discusses implications of our simple model, and develops a richer multi-task model that allows a reinterpretation of the results of Section IV. Section VI concludes.

\section{Model}

In order to understand variation in pay sensitivities across firms of different sizes, we need a model that can accommodate differences in the managerial production function. We construct a model that does this, allowing the effects of managerial action on value to differ for different size firms.

Consider a firm value production function that maps managerial actions into firm value. We assume that firm value has components that are affected by managerial effort, and components that are independent of managerial effort.

$\mathrm{V}_{\mathrm{i}, \mathrm{t+1}}=\gamma\left(\mathrm{V}_{\mathrm{it}}\right) \mathrm{a}_{\mathrm{it}}+\mathrm{V}_{\mathrm{it}}+\varepsilon\left(\mathrm{V}_{\mathrm{it}}\right)$

where: 
- $\mathrm{V}_{\mathrm{i}, t+1}$ is the value of firm $\mathrm{i}$ at the beginning of period $\mathrm{t}+1$

$\mathrm{V}_{\mathrm{it}}$ is the value of firm $\mathrm{i}$ at the beginning of period $\mathrm{t}$

$\varepsilon\left(V_{i n}\right)$ is the random component of firm value in period t. $\varepsilon$ is a normally distributed random variable with mean 0 and a standard deviation $\sigma\left(\mathrm{V}_{\mathrm{it}}\right) . \sigma\left(\mathrm{V}_{\mathrm{it}}\right)$ varies with the size of the firm.

$a_{i t}$ is the effort of the CEO of firm $i$ in period $t$

$\gamma\left(V_{i t}\right)$ is the marginal product of managerial effort. It also varies with the size of the firm.

CEOs have disutility for effort. We assume that all CEOs share the same dislike for their effort, or at least that CEOs of larger firms are not systematically different from those of smaller firms with respect to their cost of effort. ${ }^{6}$

$\mathrm{C}\left(\mathrm{a}_{\mathrm{il}}\right)=\frac{a_{i t}^{2}}{2}$

CEOs are risk averse, with negative exponential utility for wealth, and additively separable cost of effort. This implies that the utility for monetary rewards can be captured with the mean and the variance of wealth. The CEO's utility is:

$\mathrm{U}_{\mathrm{i}}\left(\mathrm{W}_{\mathrm{it}}, \mathrm{a}_{\mathrm{it}}\right)=\mathrm{E}\left(\mathrm{W}_{\mathrm{it}}\right)-\rho_{\mathrm{i}} \sigma_{W_{\mathrm{it}}}^{2}-\mathrm{C}\left(\mathrm{a}_{\mathrm{it}}\right)$,

Where:

$\mathrm{W}_{\mathrm{it}}$ is CEO i's wealth in period $\mathrm{t}$,

$E\left(W_{i t}\right)$ is the expected value of CEO i's wealth in period $t$

$\rho_{\mathrm{i}}$ is the CEO's measure of absolute risk aversion

$\sigma_{W_{i t}}^{2}$ is the variance of the CEO's wealth in period $\mathrm{t}$.

The utility function that we use has no "wealth effects." That is, rich CEOs trade off money and effort in the same way that poor CEOs do (although they may have different risk

$6 \quad$ This is a potentially troubling assumption, since more able CEOs, who could be thought of as having lower cost of effort, may tend to be selected into larger firms. We deal with this issue by subsuming cross sectional differences in effort cost into the difference in the marginal product of effort. Thus we consider CEOs with low effort cost to have high marginal products, and vice versa. This assumption has no effect on our theoretical or empirical analysis. See the discussion at the end of this section. 
tolerances). As discussed above, we believe that this simplification does not change the interpretation of our results very much.

CEO rewards in the model come from a fixed salary and the change in wealth resulting from changes in the value of stock and option holdings. Hall and Liebman (1998) have shown that variations in the value of stock and options are very large relative to variations in salary and bonus, so we restrict our attention to this component of CEO rewards, and ignore the sensitivity of salary and bonus to changes in firm value. ${ }^{7}$ We abstract from the non-linear nature of the value of options, and assume that the relationship between CEO wealth and firm value can be modeled as a simple linear function. Thus, the CEO's wealth in period $t+1$ is:

$\mathrm{W}_{\mathrm{i}, t+1}=\mathrm{W}_{\mathrm{it}}+\mathrm{S}_{\mathrm{it}}+\mathrm{b}_{\mathrm{i}}\left(\mathrm{V}_{\mathrm{i} . t+1}-\mathrm{V}_{\mathrm{it}}\right)$

where

$b_{i}$ is the CEO's effective ownership percentage ${ }^{8}$

$S_{i t}$ is a fixed component of CEO rewards, independent of firm performance.

Given this compensation scheme, the CEO chooses effort to maximize utility. The firstorder condition for this effort choice is:

$$
a_{i t}=b_{i} \gamma\left(V_{i, t}\right)
$$

In this model, the CEO's effort decision depends on the strength of the pay-forperformance relation $\left(b_{i}\right)$, and on the marginal product of effort, $\gamma_{i}$. (We now drop the explicit functional notation for $\gamma$ and $\sigma$, and refer to $\gamma\left(\mathrm{V}_{\mathrm{i}, \mathrm{l}}\right)$ as $\gamma_{\mathrm{i}}$ and $\sigma\left(\mathrm{V}_{\mathrm{it}}\right)$ as $\left.\sigma_{\mathrm{i}}\right)$.

7 We also ignore differences in "sensitivity" that might come from differential likelihood of firing. Jensen and Murphy's estimates of the incentive effect of such actions, however, suggest that they are not large. We also have no prior on how they vary with firm size. The effects of other governance differences (tighter monitoring by the board, more rigid control systems) are addressed in Section V.

* We recognize that most of an executive's stock is held voluntarily, in the sense that the firm cannot formally prevent an executive from selling stock. However, formal rules (such as stock ownership guidelines), informal pressures (including concern over market signals), and the implicit threat to renegotiate salary and bonus terms, give boards much control over CEO stock holdings. 
The optimal $b_{i}$ involves the trade-off standard in the literature: bigger b's mean better incentives for effort, but impose more risk on the CEO. This simple model yields the following familiar expression for the optimal slope of the compensation scheme:

$$
\mathrm{b}_{\mathrm{i}}^{*}=\frac{\gamma_{i}^{2}}{\gamma_{i}^{2}+2 \rho_{i} \sigma_{i}^{2}}
$$

Note that, in this expression, the more important $\mathrm{CEO}$ actions are relative to the amount of random variation in firm value (that is, the size of $\gamma_{i}$ relative to $\sigma_{i}$ ) the larger will be the optimal sensitivity of pay-to-performance.

We could use this model to predict how $b^{*}$ will change with firm size. To do this, however, would require that we know how $\gamma_{i}, \rho_{i}$, and $\sigma_{i}$ change with firm size. The latter two parameters are not a problem. If we assume constant relative risk aversion, then absolute risk aversion is inversely proportional to the CEO's wealth. If we can estimate how a CEO's wealth changes with firm size, then we can infer how a CEO's absolute risk aversion changes with firm size. In addition, the relationship between a firm's size and the standard deviation of its returns is well known. However, we don't know how the marginal product of a CEO's effort changes with firm size.

The model yields useful predictions, however, on what determines CEO incentives based on different possible relationships between $\gamma$ and firm size. The elasticity of $\gamma$ with respect to firm size is the critical parameter. If this elasticity is zero, then $\gamma$ is invariant with firm size. Under this assumption (common in the theoretical literature, and the underlying one in Jensen and Murphy (1990)), the dollar change in CEO wealth for each dollar change in firm value - that is, $b$ - determines the strength of CEO incentives. It does not matter whether the CEO owns 1 percent of a $\$ 100 \mathrm{M}$ firm, or 1 percent of a $\$ 10 \mathrm{Bfirm}$; an action that wastes $\$ 1 \mathrm{M}$ in one firm (say, the purchase of a corporate jet) also wastes $\$ 1 \mathrm{M}$ in the other, and both cost him $\$ 10,000$. Absent differences in the marginal utility of income, he will make the same choice even though the first CEO has $\$ 1 \mathrm{M}$ at stake, while the second has $\$ 100 \mathrm{M}$ at stake.

Consider now the opposite extreme: that the elasticity of $\gamma$ with respect to firm size is one. Such an assumption is implicit in much of the empirical literature (for instance, Joskow, Rose and Shepard (1993) and Gibbons and Murphy (1992). For a discussion, see Joskow and Rose (1994)). In this case, an action that has a $\$ 5 \mathrm{M}$ effect on a $\$ 100 \mathrm{M}$ firm will have a $\$ 500 \mathrm{M}$ effect on a $\$ 10 \mathrm{~B}$ firm. An example of this type of action might be the reorganization 
of the firm or a change in strategic direction. For this type of activity, CEO's actions affect firm percentage returns - the same action increases (or decreases) the value of the firm by 5 percent. Under this assumption, CEO incentives are determined not solely by b: a CEO with a 1 percent stake in a small firm has less incentive than a CEO with a 1 percent stake in a large firm. Reference to Equation 1 above shows why. Since effort is determined by $b_{i} \gamma_{i}$, and $\gamma_{i}$ increases proportionally with firm size, the strength of incentives is also proportional to $b_{i} V_{i}$. This result helps explain, and partly justify, the intuition that the dollar value of a CEO's holdings of stock and options matters to his incentives. If the CEO owns only stock, so that bV is equal to his stake ${ }^{9}$, and $\gamma$ is proportional to $\mathrm{V}$, then the CEO's stake is a good measure of the strength of his incentives.

Table 1 summarizes the differences between a model that assumes that the elasticity of $\gamma$ with respect to firm size is zero and one that assumes that this elasticity is one.

\section{Table 1}

Comparison of different assumptions about the elasticity of $\gamma$ (the marginal product of CEO effort) with respect to firm size.

\begin{tabular}{|c|c|c|}
\hline \multirow{3}{*}{$\begin{array}{l}\text { Elasticity of } \gamma \text { with respect to } \\
\text { firm size } \\
\text { The marginal product of CEO } \\
\text { actions on firm value: }\end{array}$} & \multicolumn{2}{|c|}{ Two Polar Cases } \\
\hline & 0 & 1 \\
\hline & Is invariant to firm size & $\begin{array}{l}\text { Scales proportionally with firm } \\
\text { size }\end{array}$ \\
\hline CEO actions affect: & Shareholder wealth in dollars & Shareholder returns \\
\hline $\begin{array}{l}\text { Example of type of managerial } \\
\text { action }\end{array}$ & $\begin{array}{l}\text { - Buying a corporate jet } \\
\text { - Investing in a pet project } \\
\text { - Selling an underutilized } \\
\text { asset }\end{array}$ & $\begin{array}{l}\text { - Reorganizing the firm } \\
\text { - New corporate strategy } \\
\text { - Designing a new accounting or } \\
\text { compensation system }\end{array}$ \\
\hline $\begin{array}{l}\text { Appropriate measure of } \\
\text { incentives: }\end{array}$ & $\begin{array}{l}\text { b: dollars of CEO wealth per } \\
\text { dollar of firm value created }\end{array}$ & bV: CEO "stake in the firm" \\
\hline $\begin{array}{l}\text { Appropriate specification for } \\
\text { empirical tests of pay-to- } \\
\text { performance sensitivities }\end{array}$ & Pay $=\mathrm{f}$ (Firm value $)$ & $\begin{array}{l}\text { Pay }=f(\text { Shareholder returns }) \text { or } \\
\text { Pay }=f(\text { Ln }(\text { Firm Value }))\end{array}$ \\
\hline
\end{tabular}

$9 \quad$ As discussed in footnote 4 , if the CEO also holds options with positive exercise prices, then the value of his holdings will be less than bV, since options have more incentive kick per dollar of value than 


\section{Estimating the marginal product of CEO effort}

Since we do not know how the marginal product of CEO effort changes with respect to firm size, we cannot predict how the optimal b changes with firm size. Instead, we take the opposite approach. We assume that the b's that we observe in the data are optimal (or at least not differentially biased with respect to firm size: more on this later), and use this assumption to estimate the elasticity of $\gamma$ with respect to firm size. Solving Equation (2) for $\gamma_{\mathrm{i}}$ yields:

$$
\gamma_{i}=\sqrt{\frac{2 b_{i}^{*} \rho_{i} \sigma_{i}^{2}}{1-b_{i}^{*}}}
$$

For each firm in the sample, we know $\mathrm{b}^{*}$ and $\sigma$ in a year. We must only get a handle on how $\rho_{i}$ (the measure of absolute risk aversion) varies with firm size. There is reason to suspect that it might: CEOs of larger firms are likely to be wealthier (and thus have lower levels of absolute risk aversion) than the CEOs of smaller firms. We make the assumption that all CEOs have the same level of relative risk aversion, (although we do some sensitivity analyses on this assumption in Section IV) and then use multiple estimates of how CEOs' wealth change with firm size.

Absolute risk aversion is equal to:

$\rho_{\mathrm{i}}=\frac{\alpha}{\mathrm{W}_{\mathrm{i}}}$

where $\alpha$ is the coefficient of relative risk aversion.

Since we do not know CEO wealth, we make three different assumptions about the relationship between firm size and CEO wealth.

1. CEO wealth is proportional to total annual compensation (salary, bonus and stock options valued at Black-Scholes).

2. CEO wealth is proportional to the CEO's wealth in the firm (the sum of the value of CEO stock and stock option holdings)

3. CEOs of large firms are neither richer nor poorer than CEOs of small firms.

does stock. See Hall (1998) for a discussion of this point. 
Using data on firm size, the standard deviation of returns, and each of these assumptions about the wealth of CEOs, we calculate a value for $\gamma$ for each firm in the sample. Since we are only interested in how $\gamma$ changes with firm size, we will not worry about the absolute size of $\gamma$ (whose units are arbitrary anyhow: dollars of firm value per unit of effort). Rather, we plot how $\gamma$ changes across firm size deciles, and use OLS and quantile (median) regressions to estimate the elasticity of $\gamma$ with respect to firm size.

In understanding our methodology, it is important to recognize that the actual level of relative risk aversion $(\alpha)$, as well as the multipliers that we use (for our estimates of the wealth of the CEO) are irrelevant to our estimates of changes in $\gamma$. Note that any change in the scale of $\rho_{\mathrm{i}}$ has no effect on the ratios of $\gamma$ 's, nor does it affect elasticity estimates. Since what we are investigating is how $\gamma$ changes with size, only the relationship between $\rho$ and size matters.

It is now possible to see why we can subsume cross-sectional differences in the cost of effort into our parameter for the marginal product of effort. Note that if we had assumed that CEOs' cost of effort varied with firm size, our expression for $b^{*}$ would change. Everywhere that the current expression has $\gamma_{i}^{2}$, we would need to replace it with $\gamma_{i}^{2} / C_{i}$ ", where $C_{i}{ }^{\prime}$ is the second derivative of the cost of effort function. Such a change would alter none of the analysis - it would only change the parameter that we are estimating. Instead of estimating the marginal product of CEO effort in a firm, we would be estimating ratio of this marginal product to the square root of effort cost for the CEO in this firm. This is the sense in which a CEO with a low cost of effort can be thought of as working in a firm with a high marginal product of effort. ${ }^{10}$

\section{Data Sources and Description}

We use two different sources of compensation data for our empirical estimation. Our first source is the dataset on CEO stock and option holdings used by Hall and Liebman (1998). We use the most recent year (1994) and the earliest year (1980) in their sample. The

\footnotetext{
10) Taken literally, our model predicts that if a particular CEO moves from a small firm to a large one, his marginal product will take a large jump. While this is probably true to some extent, our estimates of $\gamma$ will tend to overstate this change if C" falls with firm size. It would be possible to exploit this, and possibly disentangle the effect of a CEO's ability from the effect of a change in his marginal product by analyzing changes in incentive arrangements around CEO transitions.
} 
advantage of this data is that it contains very precise and detailed measures of how the value of a CEO's stock and stock option holdings change with changes in firm value. Hall and Liebman used the history of stock and stock option grants and sales to determine the details about each CEO's stock and stock option holdings. This is particularly important for stock options since the value and sensitivity of an option can not be determined with the BlackScholes formula without knowing the characteristics of each option - remaining maturity, dividend rate, volatility, stock price and exercise price. For example, in-the-money options have a much higher delta (the change in the option value for a derivative change in the stock price) than out-of-the-money options. The details of the methodology used to calculate CEO stock and stock option holdings are contained in the appendix of Hall and Liebman (1998).

While the advantage of Hall-Liebman dataset is its precision (in measuring $b$ and CEO wealth in the firm), the disadvantage is that it contains only a sample of the largest publicly traded firms (approximately half of the companies in the Forbes annual survey of the largest companies): 354 firms in 1994 and 333 firms in 1980. Because of this, we also use a second data set, Standard and Poor's ExecuComp, which contains a larger sample, and wider range (in terms of size), of companies. We use the most recent sample we have, which is the 1996 data set. The disadvantage of using this data is the loss in precision in measuring the value and the sensitivity of the stock option packages. ExecuComp reports only the number of in-the-money options held by the CEO, and without a long time series, it is not possible to back out the characteristics of each CEO's stock option holdings at any point in time. Nevertheless, ExecuComp has a reasonably good measure of the total number of shares and (in-the-money) options " held by each CEO and we adjust option holdings into share equivalents by multiplying each option by 0.7 , which is (approximately) the median delta in the Hall-Liebman data. ${ }^{12}$ For the noncompensation variables market value and volatility - we use CRSP. The volatility measures we use (standard deviation and variance) are annualized and based on monthly data for the previous 36

\footnotetext{
"There is also some concern that ExecuComp sometimes double counts options and shares held by the CEO. Many companies include vested options (options vested already or in the next 60 days) in their measure of beneficial ownership, leading to double counting of shares and options. However, companies typically footnote this and ExecuComp has a variable that, in principle, enables us to undo this double counting. However, this "double counting variable" is known to be somewhat inaccurate.

12 The median delta is about 0.6 for new (typically at the money) options, but the median option held by CEOs is in the money, raising the delta a bit.
} 
months, consistent with the standard practice. Summary statistics for each of the variables used in this paper are shown in Table 2.

Table 2

Summary Statistics

\begin{tabular}{|c|c|c|c|c|c|c|}
\hline & Mean & $\begin{array}{c}1^{\mathrm{si}} \\
\text { Percentile } \\
\text { Cutoff } \\
\end{array}$ & $\begin{array}{c}10^{\text {th }} \\
\text { Percentile } \\
\text { Cutoff } \\
\end{array}$ & Median & $\begin{array}{c}90^{\text {th }} \\
\text { Percentile } \\
\text { Cutoff }\end{array}$ & $\begin{array}{c}99^{\text {th }} \\
\text { Percentile } \\
\text { Cutoff }\end{array}$ \\
\hline \multicolumn{7}{|l|}{$\begin{array}{l}1996(\text { ExecuComp) } \\
n=1125\end{array}$} \\
\hline Market Value & $\$ 4.7 \mathrm{~B}$ & $\$ 52 \mathrm{M}$ & $\$ 215 \mathrm{M}$ & $\$ 1.1 \mathrm{~B}$ & $\$ 10.2 \mathrm{~B}$ & $\$ 54.5 \mathrm{~B}$ \\
\hline Variance of Mkt Value & $\$ 9.1 \mathrm{e}+18$ & $\$ 6.1 e+14$ & $\$ 5.9 e+15$ & $\$ 1.5 \mathrm{e}+17$ & $\$ 6.6 \mathrm{e}+18$ & $\$ 2.0 \mathrm{e}+20$ \\
\hline Firm Sales & $\$ 4.0 \mathrm{~B}$ & $\$ 23 \mathrm{M}$ & $\$ 177 \mathrm{M}$ & $\$ 1.1 \mathrm{~B}$ & $\$ 9.3 \mathrm{~B}$ & $\$ 38.5 \mathrm{~B}$ \\
\hline Total Compensation & $\$ 2.67 \mathrm{M}$ & $\$ 200 \mathrm{~K}$ & $\$ 468 \mathrm{~K}$ & $\$ 1.36 \mathrm{M}$ & $\$ 4.94 \mathrm{M}$ & $\$ 18.4 \mathrm{M}$ \\
\hline CEO Wealth in the Firm & $\$ 75.9 \mathrm{M}$ & $\$ 430 \mathrm{~K}$ & $\$ 1.02 \mathrm{M}$ & $\$ 10 \mathrm{M}$ & $\$ 90 \mathrm{M}$ & $\$ 789 \mathrm{M}$ \\
\hline b & .0332 & .0002 & .0016 & .0116 & .0939 & .3117 \\
\hline \multicolumn{7}{|l|}{$\begin{array}{l}1994 \text { (Hall-Liebman) } \\
n=352\end{array}$} \\
\hline Market Value & $\$ 4.8 \mathrm{~B}$ & $\$ 94 \mathrm{M}$ & $\$ 668 \mathrm{M}$ & $\$ 2.4 \mathrm{~B}$ & $\$ 10.8 \mathrm{~B}$ & $\$ 39.0 \mathrm{~B}$ \\
\hline Variance of Mkt Value & $\$ 3.6 \mathrm{e}+18$ & $\$ 1.72 \mathrm{e}+15$ & $\$ 2.4 e+16$ & $\$ 3.3 e+17$ & $\$ 6.5 e+18$ & $\$ 1.5 \mathrm{e}+20$ \\
\hline Firm Sales & $\$ 6.2 \mathrm{~B}$ & $\$ 252 \mathrm{M}$ & $\$ 991 \mathrm{M}$ & $\$ 3.2 \mathrm{~B}$ & $\$ 13.3 \mathrm{~B}$ & $\$ 53.8 \mathrm{~B}$ \\
\hline Total Compensation & $\$ 2.48 \mathrm{M}$ & $\$ 325 \mathrm{~K}$ & $\$ 573 \mathrm{~K}$ & $\$ 1.48 \mathrm{M}$ & $\$ 4.65 \mathrm{M}$ & $\$ 18 \mathrm{M}$ \\
\hline CEO Wealth in the Firm & $\$ 22.9 \mathrm{M}$ & $\$ 150 \mathrm{~K}$ & $\$ 900 \mathrm{~K}$ & $\$ 5.24 \mathrm{M}$ & $\$ 45 \mathrm{M}$ & $\$ 302 \mathrm{M}$ \\
\hline b & .0250 & .00005 & .0006 & .0053 & .0475 & .3336 \\
\hline \multicolumn{7}{|l|}{$\begin{array}{l}1980 \text { (Hall-Liebman) } \\
\mathrm{n}=349\end{array}$} \\
\hline Market Value & $\$ 953 \mathrm{M}$ & $\$ 24 \mathrm{M}$ & $\$ 66 \mathrm{M}$ & $\$ 425 \mathrm{M}$ & $\$ 1.9 \mathrm{~B}$ & $\$ 9.3 \mathrm{~B}$ \\
\hline Variance of Mkt Value & $\$ 2.0 \mathrm{e}+17$ & $\$ 6.5 e+13$ & $\$ 3.6 e+14$ & $\$ 1.3 \mathrm{e}+16$ & $\$ 3.0 \mathrm{e}+17$ & $\$ 6.0 \mathrm{e}+18$ \\
\hline Firm Sales & $\$ 2.8 \mathrm{~B}$ & $\$ 102 \mathrm{M}$ & $\$ 267 \mathrm{M}$ & $\$ 1.1 \mathrm{~B}$ & $\$ 6.1 \mathrm{~B}$ & $\$ 26.6 \mathrm{~B}$ \\
\hline Total Compensation & $\$ 806 \mathrm{~K}$ & $\$ 194 \mathrm{~K}$ & $\$ 281 \mathrm{~K}$ & $\$ 600 \mathrm{~K}$ & $\$ 1.43 \mathrm{M}$ & $\$ 3.4 \mathrm{M}$ \\
\hline CEO Wealth in the Firm & $\$ 7.75 \mathrm{M}$ & $\$ 70 \mathrm{~K}$ & $\$ 341 \mathrm{~K}$ & $\$ 1.8 \mathrm{M}$ & $\$ 15.5 \mathrm{M}$ & $\$ 130 \mathrm{M}$ \\
\hline $\mathrm{b}$ & .0243 & 0 & .0002 & .0023 & .0679 & .2982 \\
\hline
\end{tabular}

Note: $b$ is the dollar change in CEO wealth for each dollar change in firm value.

\section{Empirical Results}

Our empirical results fall into two categories: the relationship between the marginal product of effort $(\gamma)$ and firm size, and the relationship between incentive strength $\left(b^{*} \gamma\right)$ and size. We estimate each for three measures of $\gamma$ (based on the three assumptions about the relationship between firm size and CEO wealth noted above) and three time periods: 1980 , 
1994 (Hall-Liebman) and 1996 (ExecuComp). Because our measure of b contains numerous outliers, we use quantile (median) regressions as well as OLS in our estimations.

\section{CEO marginal productivity $(\gamma)$ and firm size}

In order to see the basic trends in the data, we begin by grouping the data into size deciles, and plotting median $\gamma$ against the median size for each decile. We do this for each of the three measures of the $\gamma$-size relationship. The $\gamma$ s are normalized to one in the first decile; since their units are arbitrary, only their relative slopes have meaning. Figure 2 show sthe plots for the years 1996, 1994 and 1980. Note that in all cases and for all years, $\gamma$ rises with firm size. Indeed, in most cases the relationship is monotonic. A nonparametric test (Cuzick, 1985) ${ }^{1.3}$ that tests for an upward trend in the medians easily rejects (at the one percent confidence level) the null hypothesis that there is no upward trend. Note that $\gamma$ rises fastest with size in the (probably unrealistic) case where CEO wealth is assumed to be constant across firm size. We view the first two wealth assumptions as most plausible and report the third as a robustness check to see how sensitive our estimates are to changes in the wealth assumption.

In order to estimate an elasticity of $\gamma$ with respect to firm size, we regress the log of $\gamma$ on the log of size for each of the three years and each of the three measures of $\gamma$. We estimate OLS and quantile (median) regressions. For each regression, we report the coefficient and $\mathrm{t}$-tests against the null hypotheses of the two polar cases we have described: that the elasticities are equal to zero (no relationship between $\gamma$ and size) and one (that there is a proportional relationship between $\gamma$ and size).

13 This test is NPTREND in STATA, version 4.0. This test is a "trend" version of the Wilcoxen (1945) nonparametric test of the hypothesis that two samples are from populations that have the same median (SIGNTEST in STATA). 
Figure 2:

Relationship between CEO marginal product and firm size
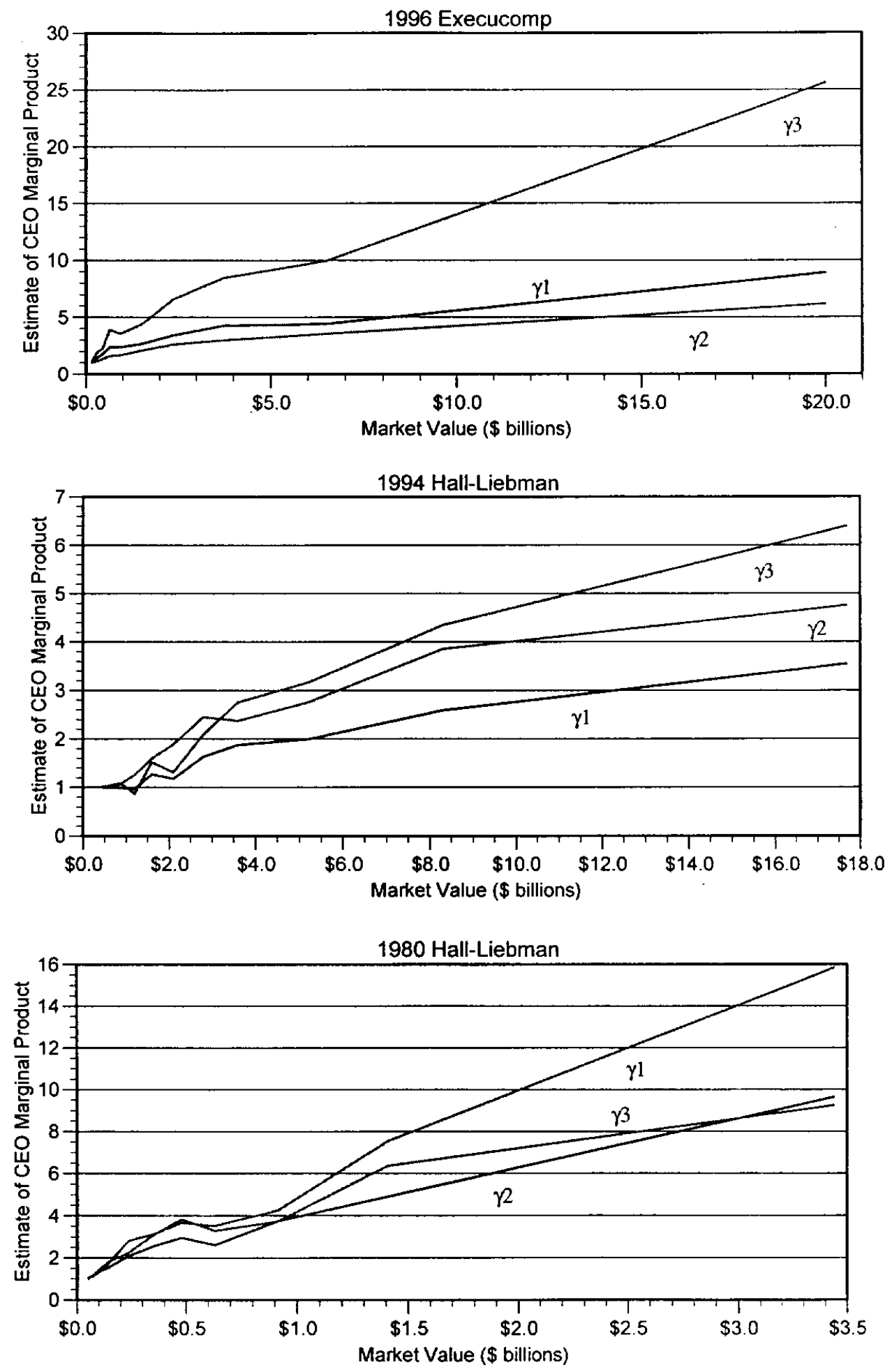

Medians for each decile are plotted. $\gamma 1$ assumes that CEO wealth is proportional to compensation; $\gamma$ assumes that CEO wealth is proportional to the CEO's stake in the firm; $\gamma$ assumes that CEO wealth is constant 
The results are reported in Table 3. The point estimates for the elasticity are in the $0.4 \pm$ 0.1 range in all specifications except for those in which wealth is assumed to be constant across size, in which case the elasticities are, as expected, a bit higher and in the range of 0.6. In all cases, both null hypotheses are strongly rejected at conventional levels of significance. For all years and all specifications, the elasticity estimates are neither zero nor one. In addition, the fit of the model is surprisingly good. The adjusted $\mathrm{R}^{2}$ in most of the regressions are quite high. It appears that firm size is an important determinant of the marginal product of CEO effort.

\section{Table 3}

The Elasticity of CEO Marginal Product $(\gamma)$ with Respect to Firm Size

The dependent variable is $\ln (\gamma)$ and the independent variable is $\ln ($ firm size).

OLS

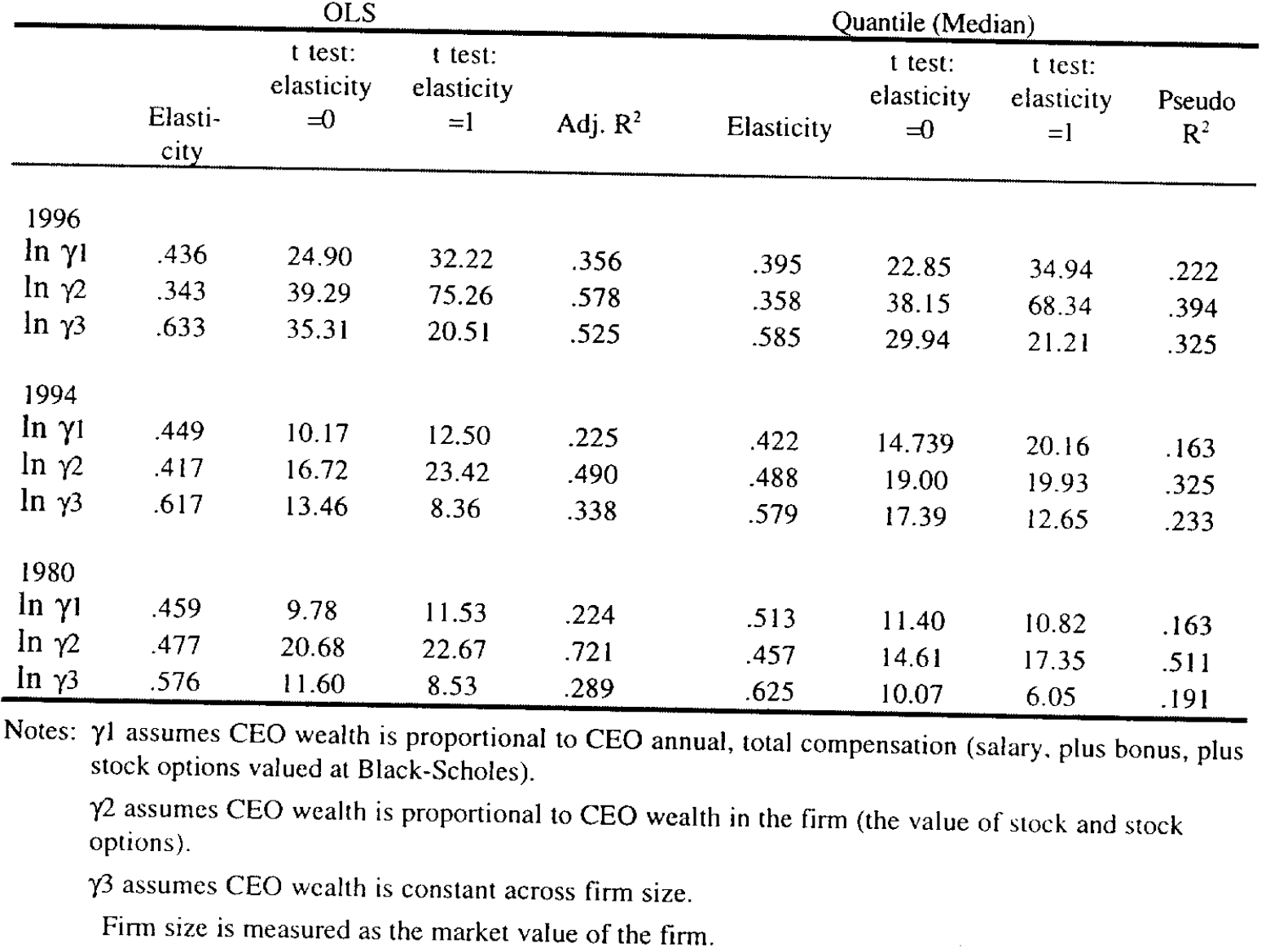


To determine how sensitive our results are to various assumptions, we conduct two robustness checks. The first involves varying the degree of CEO risk aversion since this is a key parameter in the model. While there is good reason to believe that absolute risk aversion declines with firm size (since CEOs of large firms are wealthier), it is less clear how a CEOs coefficient of relative risk aversion changes (on average) as firm size changes. So far, we have assumed it is constant. Nevertheless, it is useful to see how our elasticity estimates change if CEO relative risk aversion $(\alpha)$ differs by firms size.

To check the sensitivity of our estimates to changes in relative risk aversion, we vary $\alpha$ by a factor of two for the firms in our sample(s). ${ }^{14}$ More precisely, we assign the smallest firm (in terms of market value) in our sample an $\alpha$ that is twice as large as the $\alpha$ for the largest firm in our sample, and use linear interpolation to assign the $\alpha$ 's for the intermediate firms. The regressions, which are otherwise analogous to those in Table 3, are shown in the first column of Table 4. Only OLS estimates are shown since the quantile regressions were substantively similar and added little new information.

Comparison with the corresponding estimates in Table 3 indicates that the elasticity estimates decreased as would be expected, but by a very small amount -- typically by about 0.01 . For example, the first elasticity declines from .436 to .427 . The key implication of this sensitivity analysis is that the elasticity estimates are not too sensitive to changes in CEO risk aversion. It would take extremely large differences in risk aversion between CEOs in large and small firms to push the elasticity estimate anywhere near the polar cases of zero or one.

Our second robustness check involves using a different measure of firm size. We run specifications with $\ln$ (sales) replacing $\ln$ (market value) as the independent variable, since sales is perhaps a less noisy proxy for the scale of the firm. The results, shown in Table 4, are qualitatively similar, but the elasticity estimates are a bit lower, ranging from .26 to .42 (and again, they are higher for the $\ln (\gamma 3)$ specification). The adjusted R-squared statistics are also a bit lower. (Again, only OLS estimates are reported since the quantile estimates

\footnotetext{
it Since only proportion matters (how risk aversion $(\alpha / \mathrm{W})$ varies with size), we could also vary the denominator (instead of the numerator) by making other assumptions about the relationship between CEO wealth and size. But changing $\alpha$ allows us to be precise about the thought experiment. In this case, we are changing risk aversion by a factor of two (on top of the various assumptions we made earlier about the CEO wealth-firm-size relationship).
} 
are quite similar.) Nevertheless, the coefficients are precisely estimated, and not close to either one or zero in any of the specifications.

\section{Table 4}

The Elasticity of CEO Marginal Product $(\gamma)$ with Respect to Size

Robustness checks: OLS regressions varying risk aversion with size, and using sales as the measure of size.

\begin{tabular}{|c|c|c|c|c|}
\hline & \multicolumn{4}{|c|}{$\gamma$ increases with firm size* } \\
\hline & \multirow[b]{2}{*}{$\begin{array}{c}\text { Coefficient on } \\
\ln \text { (mkt.val.) } \\
\text { (standard error) }\end{array}$} & \multirow[b]{2}{*}{ Adj. $R^{2}$} & \multicolumn{2}{|c|}{ Ln (sales) is the size measure ${ }^{* *}$} \\
\hline & & & $\begin{array}{c}\text { Coefficient on } \\
\operatorname{Ln} \text { (sales) } \\
\text { (standard error) }\end{array}$ & Adj. $R^{2}$ \\
\hline \multicolumn{5}{|c|}{ (staliudra eirtor) } \\
\hline $\ln \gamma 1$ & $.427(.017)$ & .35 & $.261(.020)$ & .13 \\
\hline $\ln \gamma 2$ & $.334(.009)$ & .44 & $.262(.011)$ & .34 \\
\hline $\ln \gamma 3$ & $.624(.018)$ & .52 & $.434(.022)$ & .25 \\
\hline \multicolumn{5}{|l|}{1994} \\
\hline $\ln \gamma 1$ & $.429(.044)$ & .21 & $.419(.051)$ & .19 \\
\hline $\ln \gamma 2$ & $.400(.025)$ & .47 & $.300(.034)$ & .25 \\
\hline $\ln \gamma 3$ & $.597(.046)$ & .32 & $.600(.055)$ & .29 \\
\hline \multicolumn{5}{|l|}{1980} \\
\hline $\ln \gamma 1$ & $.450(0.50)$ & .22 & $.408(.058)$ & .15 \\
\hline $\ln \gamma_{2}$ & $.469(.023)$ & .72 & $.425(.037)$ & .49 \\
\hline $\ln \gamma 3$ & $.568(.050)$ & .28 & $.539(.061)$ & .22 \\
\hline
\end{tabular}

Notes: $\gamma 1$ assumes wealth is proportional to total compensation.

$\gamma 2$ assumes wealth is proportional to wealth in the firm (the value of stock and stock options).

$\gamma 3$ assumes wealth is constant across firm size.

* For these regressions, it is assumed that $\alpha$ decreases by a factor of two (linearly) as company size increases from smallest to largest. All other assumptions are the same as in Table 3.

** These regressions are the same as those in Table 3, but In(market value) is replaced with in (sales). For both sets of regressions, quantile (median) regressions produced very similar results and are therefore not reported.

In Table 5, we add industry controls to our estimates of the elasticity of marginal product. We do so by adding 59 dummy variables, one for each of the 2-digit SIC's represented by the firms in our sample, to the regressions reported in Table 3. A comparison of the first column of Table 5 with the first column of Table 3 shows that the coefficients on $\ln (\gamma)$ change hardly at all. In addition, only one of the industry dummies, that for regulated 


\section{Table 5}

The Elasticity of CEO Marginal Product $(\gamma)$ with Respect to Firm Size, Controlling for SIC

The dependent variable is $\ln (\gamma)$ and the independent variables are $\ln$ (market value) and 59 industry dummies. Standard errors are in parentheses.

\begin{tabular}{llll}
\hline & Ln(size) & $\begin{array}{l}\text { Regulated } \\
\text { Utilitities }\end{array}$ & Adj. $\mathrm{R}^{2}$ \\
\hline 1996 & & & \\
$\ln \gamma 1$ & $.468(.017)$ & $-1.35(.20)^{*}$ & .499 \\
$\ln \gamma 2$ & $.361(.009)$ & $-0.55(.10)^{*}$ & .661 \\
$\ln \gamma 3$ & $.673(.016)$ & $-1.07(.19)^{*}$ & .678 \\
& & & \\
1994 & & & \\
$\ln \gamma 1$ & $.404(.046)$ & $-1.26(.17)^{*}$ & .414 \\
$\ln \gamma 2$ & $.422(.028)$ & $-0.25(.12)^{*}$ & .561 \\
$\ln \gamma 3$ & $.578(.045)$ & $-1.65(.16)^{*}$ & .561 \\
& & & \\
1980 & & & .519 \\
$\ln \gamma 1$ & $.379(.050)$ & $-1.34(.21)^{*}$ & .748 \\
$\ln \gamma 2$ & $.433(.029)$ & $-0.34(.18)$ & .514 \\
$\ln \gamma 3$ & $.513(.052)$ & $-1.70(.21)^{*}$ & \\
\hline
\end{tabular}

Notes: $\gamma 1$ assumes wealth is proportional to total compensation

$\gamma 2$ assumes wealth is proportional to wealth in the firm (the value of stock and stock options). $\gamma \beta$ assumes wealth is constant across firm size.

* indicates significance at the $5 \%$ level.

Quantile (median) regressions produced very similar results and are therefore not reported.

utilities (SIC 49), is consistently significant. We report the size of this coefficient (minus the average size of the other 58 dummy coefficients) in the second column of Table 5 . As can be seen, the dummy on regulated utilities is negative. The magnitude of this coefficient suggests that the marginal product of CEO effort in this industry is somewhere between $22 \%$ and $82 \%$ lower than the average marginal products of CEOs in other industries. Such a finding is consistent with the hypothesis suggested by Joskow, Rose and Shepard (1993) that regulations constrain the discretion of the CEOs in regulated industries, and with Palia's (1998) finding that regulated firms attract lower quality managers.

There are two additional points worth mentioning about these estimates. First, it is interesting that our most plausible estimate of the $\gamma$-size elasticity is about 0.4 (and closer to 0.3 when sales is the proxy for firm size). These estimates are strikingly close to the 0.3 estimates of the elasticity on the level of CEO pay with respect to size (Murphy 1985, Rosen 1992). Rosen's explanation for the increase in CEO pay with firm size is that the 
marginal product of the CEO rises with size. Is the marginal product that we are estimating in this paper the same one that determines wages in the market for CEOs? Although beyond the scope of this paper, we find this to be an intriguing possibility and one worth further study.

Second, it is worth emphasizing that our results are based on the assumption that the b's are optimal on average. More precisely, our analysis requires that the b's are not differentially optimal across firms of different sizes. This may not be the case. Jensen and Murphy (1990) have suggested that public and private political forces reduce the pay-toperformance sensitivity of CEOs. To the extent that they are correct, we suspect that these forces would be stronger in larger firms, creating a downward bias in b that is larger for larger firms. In this case, the true firm-size elasticity is larger than the one we have estimated, since optimal b's higher than what we observe would imply a higher $\gamma$. Although we have no way of testing this formally, we are confident that this bias does not change the basic findings in this paper.

\section{Incentive strength $\left(\gamma^{*} b\right)$ and firm size}

As Rosen (1992) and Holmstrom (1992) have argued, the relationship between firm size and incentives has not been carefully analyzed. One exception is Schaefer (1998), who estimates that pay-to-performance sensitivities are inversely proportional to the square root of firm size, which is equivalent to finding that the elasticity of b with respect to firm size is -0.5. The inverse relationship between pay-to-performance and firm size is also strongly present in our data, as shown in Figure 1. In addition, Schaefer's result also holds for our data and measure of $b$. We regress $\ln (\mathrm{b})$ on $\ln$ (size) and estimate an elasticity of -0.48 for the 1996 ExecuComp data and -0.55 for the 1994 Hall-Liebman data. Both estimates are highly significant.

However, the strongly declining pay to performance sensitivity does not imply that "incentive strength" declines in a similar way, although pay-to-performance sensitivities are sometimes loosely interpreted as measures of incentive strength. Given that the marginal product of CEO effort $(\gamma)$ rises with firm size, while $b$ falls with firm size, what are the implications for managerial effort (broadly defined) across firm size? Recall from the model (Equation 1) that managerial effort is determined by $b^{*} \gamma$. While the standard model (which yields effort proportional to $b$ since $\gamma$ is often assumed to be constant) predicts that CEOs of large firms expend much less effort than CEOs of small companies, our model 
makes no such prediction. Indeed, if $\gamma$ rises fast enough with firm size, it is possible to get the opposite result. We use our estimates of $\gamma$ for each firm to test the hypothesis that the CEOs of large firms have weaker incentives and work less hard than those of small firms by looking at the relationship between $b^{*} \gamma$ and firm size.

In order to examine this issue, we conduct a similar set of tests as above, with $b^{*} \gamma$ replacing $\gamma$. Two sets of regressions are reported in Tables 6 and 7 and the decile plots are shown in Figure 3. Table 6 reports regressions analogous to those in Table 3. Table 7 contains the same result in levels rather than logs since it is not clear that the log-log specification is appropriate (and an elasticity has no special meaning here).

\section{Table 6}

The Relationship Between Incentive Strength (or Effort) and Firm Size The dependent variable is $\ln \left(\mathrm{b}^{*} \gamma\right)$ and the independent variable is $\ln$ (firm size).

\begin{tabular}{|c|c|c|c|c|c|c|}
\hline \multicolumn{3}{|c|}{ OLS } & \multicolumn{4}{|c|}{ Quantile (Median) } \\
\hline & Coef. & $\mathrm{T}$ ratio & Adj. $R^{2}$ & Coef. & $\mathrm{T}$ ratio & Pseudo $R^{2}$ \\
\hline 1996 & & & & & & \\
\hline $\ln \left(b^{*} \gamma l\right)$ & -.039 & -0.89 & .0002 & -.106 & -2.65 & .006 \\
\hline $\ln \left(b^{*} \gamma 2\right)$ & -.133 & -4.42 & .016 & -.196 & -6.16 & .028 \\
\hline $\ln \left(b^{*} \gamma 3\right)$ & .159 & 6.19 & .032 & .070 & 1.41 & .001 \\
\hline 1994 & & & & & . & \\
\hline $\ln \left(b^{*} \gamma 1\right)$ & -.099 & -.843 & -.001 & -.190 & -2.49 & .005 \\
\hline $\ln \left(b^{*} \gamma 2\right)$ & -.185 & -2.80 & .023 & -.184 & -2.99 & .017 \\
\hline $\ln \left(b^{*} \gamma \beta\right)$ & .070 & 0.58 & -.002 & -.004 & -0.04 & .0001 \\
\hline 1980 & & & & & & \\
\hline $\ln \left(b^{*} \gamma l\right)$ & -.231 & -1.81 & .010 & -.076 & -.597 & .001 \\
\hline $\ln (b * \gamma 2)$ & -.225 & -2.92 & .044 & -.157 & -2.42 & .019 \\
\hline $\ln \left(b^{*} \gamma 3\right)$ & -.113 & -0.86 & -.0008 & -.028 & -0.18 & .0003 \\
\hline
\end{tabular}

Notes: $\gamma l$ assumes CEO wealth is proportional to CEO annual, total compensation (salary, plus bonus, plus stock options valued at Black-Scholes).

$\gamma$ assumes CEO wealth is proportional to CEO wealth in the firm (the value of stock and stock options).

$\gamma 3$ assumes CEO wealth is constant across firm size.

Firm size is eaual to the market value of the firm 
Table 7

The Relationship Between Incentive Strength (or Effort) and Firm Size The dependent variable is $b^{*} \gamma$ and the independent variable is firm size.

\begin{tabular}{|c|c|c|c|c|c|c|}
\hline & \multicolumn{3}{|c|}{ OLS } & \multicolumn{3}{|c|}{ Quantile (Median) } \\
\hline & Coefficient & Tratio & Adj. $R^{2}$ & Coefficient & T ratio & Pseudo $\mathrm{R}^{2}$ \\
\hline 1996 & & & & & & \\
\hline$b^{*} \gamma 1$ & $5.55 \mathrm{e}-06$ & 3.81 & .012 & $-4.96 \mathrm{e}-09$ & -1.53 & .0001 \\
\hline$b^{*} \gamma_{2}$ & $1.31 \mathrm{e}-08$ & 2.17 & .003 & $-3.62 \mathrm{e}-09$ & -3.06 & .004 \\
\hline$b^{*} \gamma 3$ & .0025 & 4.84 & .012 & $*$ & & \\
\hline 1994 & & & & & & \\
\hline$b^{*} \gamma 1$ & $2.40 \mathrm{e}-06$ & 2.26 & .012 & $-4.80 \mathrm{e}-09$ & -1.68 & .0001 \\
\hline$b * \gamma 2$ & $-1.45 \mathrm{e}-08$ & -1.82 & .008 & $-2.53 e-09$ & -1.72 & .004 \\
\hline$b^{*} \gamma 3$ & .0016 & 2.28 & .012 & $-2.15 e-06$ & -0.37 & .005 \\
\hline 1980 & & & & & & \\
\hline $\mathrm{b}^{*} \gamma 1$ & $-1.94 \mathrm{e}-07$ & -0.58 & -.002 & $-9.34 \mathrm{e}-10$ & -0.70 & .0001 \\
\hline $\mathrm{b}^{*} \gamma_{2}$ & $-1.47 e-08$ & -1.58 & .009 & $-2.12 \mathrm{e}-09$ & -1.76 & .006 \\
\hline$b^{*} \times 3$ & -.0001 & -0.53 & -.002 & $-7.42 \mathrm{e}-07$ & -0.56 & .0000 \\
\hline
\end{tabular}

Note: $b^{*} \gamma 1$ assumes wealth is proportional to total compensation.

$b^{*} \gamma 2$ assumes wealth is proportional to wealth in the firm (the value of stock and stock options).

$b^{*} \gamma \beta$ assumes wealth is constant across firm size.

Firm size is equal to the market value of the firm.

* Convergence was not achieved.

The results are ambiguous. Many of coefficients are negative, but the signs and significance levels are not robust across specifications. Most of the elasticity estimates in Table 6 are negative, with the quantile regression results (which are less sensitive to outliers) giving fairly consistent and significant negative coefficients. In Table 7, the levels specification yields generally positive coefficients in the OLS regression, and generally negative (but insignificant) results in the quantile regressions. In addition, the adjusted $\mathrm{R}^{2}$ in these regressions is very near zero. Size, logged or unlogged, explains almost none of the variation in incentive strength. 
Figure 3 :

Relationship between CEO incentiv es and firm size
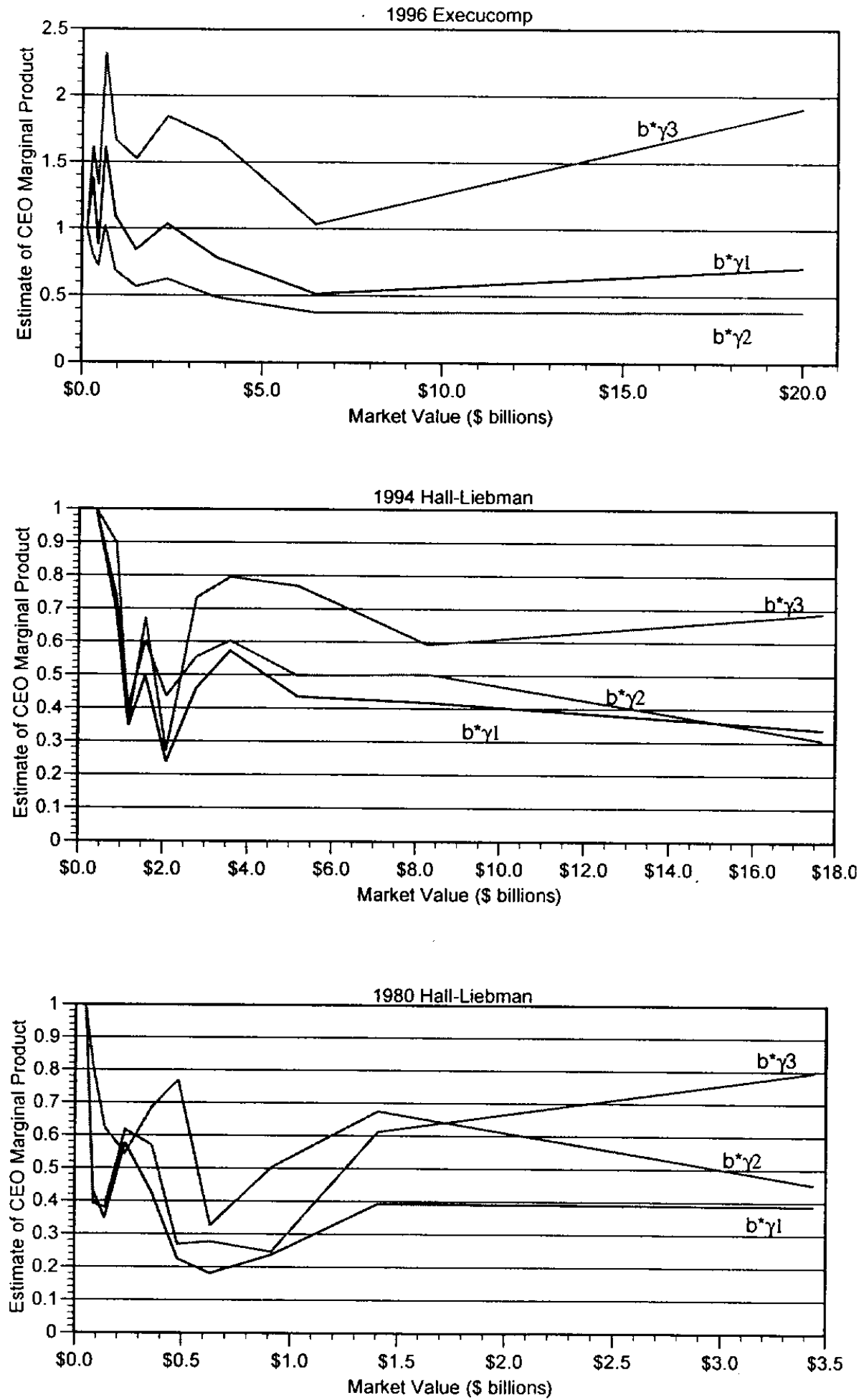

Medians for each decile are plotted. $\gamma 1$ assumes that CEO wealth is proportional to compensation: $\gamma 2$ assumes that CEO wealth is proportional to the CEO's stake in the firm; $\beta$ assumes that CEO wealth is constant 
The ambiguity of the results is not surprising given the plots shown in Figure 3 . The plots show a jagged but slightly downward trend. But the relationship is not monotonic, and it is not robust to different specifications. We therefore interpret these results with caution. The data provide no strong evidence of a correlation between incentive strength and firm size. If anything, there is a weak indication that the relationship is negative.

These findings underscore the importance of the distinction between pay-to-performance and pay-to-effort (incentive strength) in cross sectional data. In estimating pay-toperformance, researchers have used different specifications, and (partially as a result), have generated very different estimates of pay sensitivities. Underlying these different specifications and different interpretations of incentive strength has been a different set of assumptions about how managerial actions affect firm value.

As an illustration, Figure 4 shows how two different definitions of pay sensitivity, common in the empirical literature, vary with firm size. The first definition is the "dollaron-dollar" measure of pay sensitivity: how much does CEO wealth change for each dollar change in firm value. As was reported in Figure 1, this measure drops dramatically with firm size.

Figure 4:

Two measures of CEO pay sensitiivity

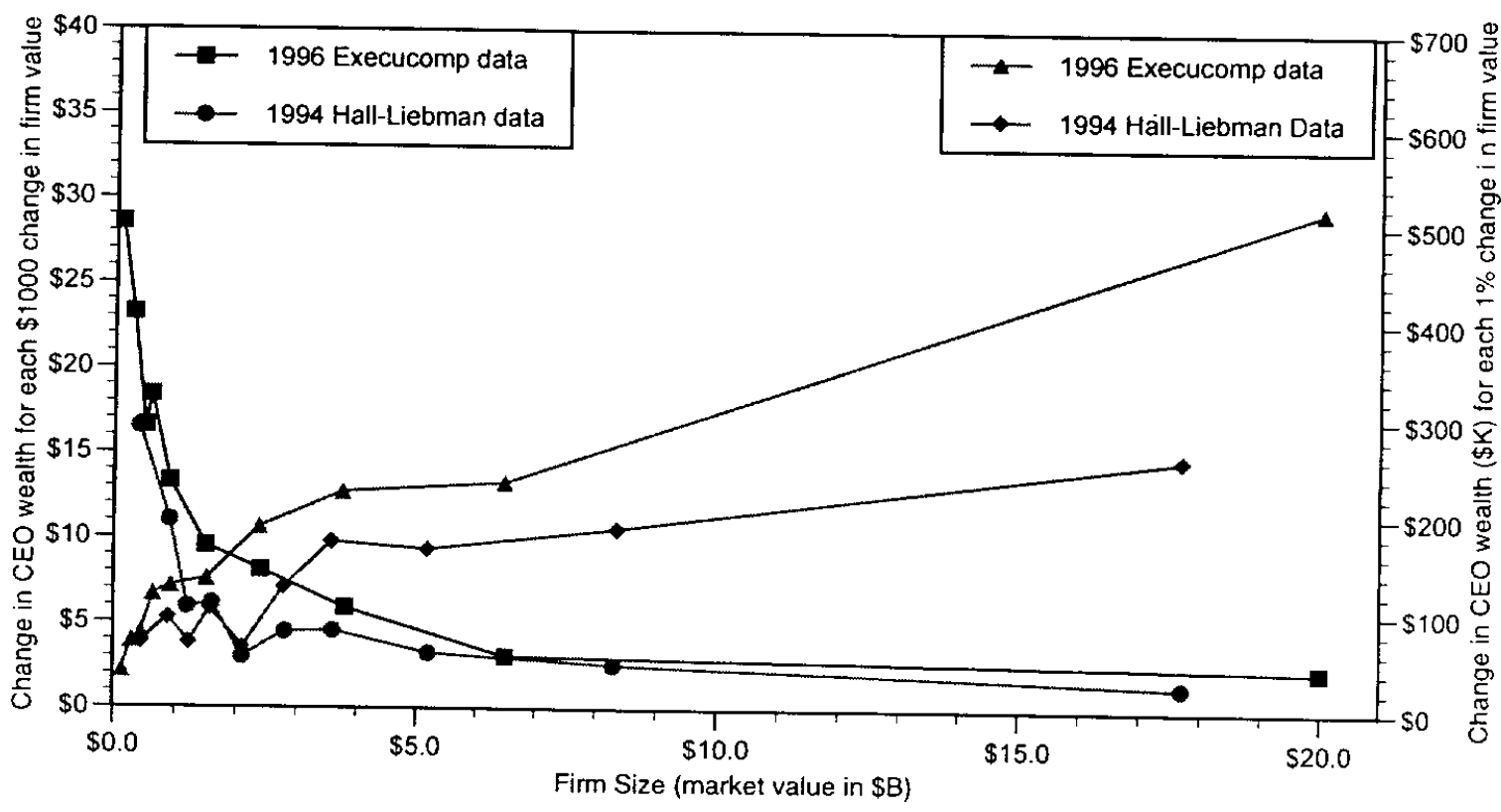

Note: Medians for each size decile are plotted 
The second measure of pay sensitivity shows how CEO wealth changes for each $1 \%$ chnage in firm value (implicit in regressions with returns on the right hand side). This measure increases with firm size! These two measures of pay sensitivity implicitly embed the two polar assumptions discussed above about how CEO marginal products vary with firm size. ${ }^{15}$ Note the different implications of these two implicit assumptions. If pay-toperformance measures are interpreted as measures of incentive strength, then specifications with changes in dollar value on the right hand side lead to the conclusion that incentives are much weaker in large firms, while specifications with percent changes on the right hand side lead to the opposite conclusion.

Our analysis suggest that neither is correct. Both measures in Figure 4 reflect extreme assumptions about the relationship between CEO productivity and firm size. When the appropriate, intermediate relationship between CEO productivity and firm size is taken into account, the relationship between incentives and firm size is shown to be between the two extremes shown in the graph: in the aggregate, incentives are roughly constant, or fall a bit, as firm size increases.

\section{Implications and Extensions}

We turn now to examine the implications of these results for the interpretation of CEO "incentive strength," firm structure, and the design of control systems. In order to fully understand the results, we will need to develop the theoretical model more fully, using a multi-task framework.

\section{Paying for performance versus paying for effort}

Our analysis has important implications for how estimates of the pay-to-performance relationship are interpreted. Pay-to-performance estimates are often interpreted as measures of the strength of incentives. But as Equation 1 shows, effort levels are determined by what might be called "pay-to-effort," not pay-to-performance. Our analysis breaks the link between pay-to-performance and pay-to-effort in cross sectional data, by allowing the

\footnotetext{
15 They also correspond to Holmstrom's (1992) two models of pay sensitivity. Holmstrom (1992) claims that what he calls the "geometric form" (in which the elasticity of $\gamma$ with respect to firm size is one, as contrasted with the "arithmetic form" in which the elasticity is zero) is better, based in part on its fit with the data.
} 
marginal product of effort to vary by firm size (and also by industry). As is clear from our analysis, incentives are determined not only by the pay-to-performance (b), but by the combination of $b$ and the marginal product of effort. CEOs with high marginal products may have powerful incentives, even if their b's are quite small. Our analysis urges caution in interpreting a sensitivity estimate as measure of incentive strength.

\section{Firm size and structure}

If the marginal product of CEO effort for a large firm is many times that for a CEO of a small firm, what implications does this have for organization structure? Since neither person has more than 24 hours available in the day, the value to firms of CEOs "leveraging" their time is greater for large firms then for small ones since the CEO's marginal productivity is much higher. Large staffs and the hiring of high-priced consultants by large company CEOs are a likely consequence. If it is true, as our elasticity estimate of about 0.4 suggests, that the marginal product of CEO effort is 400 times higher for the CEO of IBM (with a market value of $\$ 120 \mathrm{~B}$ ) than for XYZ corporation (market value $\$ 120 \mathrm{M}$ ), then it is no surprise that the CEO of IBM has a staff of hundreds, while the CEO of XYZ has only a secretary.

Of course, it is important to recognize that the estimates of marginal product that we provide in Section IV are really averages across a CEO's many activities. In fact, CEOs take many actions, some of which affect firm value in dollars (like the purchase of a jet), and some of which affect the value of the firm in percentage terms (like conceiving a new corporate strategy). In order to explore this insight more fully, we develop a multi-tasking model of CEO effort and reinterpret our empirical results in light of this model.

\section{A multi-task model of CEO value creation}

We enrich the model developed in Section II by introducing a large number of tasks in which a CEO engages. For each task, the marginal product may differ, and the relationship between the marginal product and firm size may differ. Thus, in this model, CEOs can engage in both "jet-like" and "strategy-like" activities.

Consider the following modification to the model presented above.

$$
\mathrm{V}_{\mathrm{i}, t+1}=\sum_{\mathrm{j}=1}^{\mathrm{n}} \gamma_{\mathrm{j}}\left(V_{\mathrm{it}}\right) a_{\mathrm{itj}}+\mathrm{V}_{\mathrm{it}}+\varepsilon\left(\mathrm{V}_{\mathrm{it}}\right)
$$

where: 
$\mathrm{V}_{\mathrm{i}, t+1}$ is the value of firm $\mathrm{i}$ at the beginning of period $\mathrm{t}+1$

$\mathrm{V}_{\mathrm{it}}$ is the value of firm $\mathrm{i}$ at the beginning of period $\mathrm{t}$

$\varepsilon\left(\mathrm{V}_{\mathrm{it}}\right)$ is the random component of firm value in period t. $\varepsilon$ is a normally distributed random variable with mean 0 and a standard deviation $\sigma\left(V_{i t}\right) . \sigma\left(V_{i t}\right)$ varies with the size of the firm.

$\mathrm{a}_{\mathrm{itj}}$ is the effort of the CEO of firm $\mathrm{i}$ in period $\mathrm{t}$ on task $\mathrm{j}$. There are $\mathrm{n}$ tasks that the CEO engages in.

$\gamma_{j}\left(V_{i t}\right)$ is the marginal product of managerial effort on task $\mathrm{j}$. There are $\mathrm{n}$ marginal products to go along with the $\mathrm{n}$ tasks. Some of these marginal products could be zero. Each marginal product also varies with the size of the firm.

CEOs have disutility for effort on each task. Again, we assume that all CEOs share the same dislike for their effort on each task, but we could include a task- and firm-specific cost of effort term, that would affect the optimal effort choice. Such a firm- and taskspecific cost term can again be subsumed into the marginal product of effort. Total cost of effort is:

$\mathrm{C}\left(\mathrm{a}_{\mathrm{it1}}, \mathrm{a}_{\mathrm{it} 2}, \ldots, \mathrm{a}_{\mathrm{itn}}\right)=\sum_{\mathrm{j}=1}^{\mathrm{n}} \frac{\mathrm{a}_{\mathrm{itj}}^{2}}{2}$

CEOs' risk aversion and utility for wealth are identical to the model above:

$\mathrm{U}_{\mathrm{i}}\left(\mathrm{W}_{\mathrm{it}}, \mathrm{a}_{\mathrm{it}}\right)=\mathrm{E}\left(\mathrm{W}_{\mathrm{it}}\right)-\rho_{\mathrm{i}} \sigma_{W_{i t}}^{2}-\mathrm{C}\left(\mathrm{a}_{\mathrm{it} 1}, \mathrm{a}_{\mathrm{it} 2}, \ldots, \mathrm{a}_{\mathrm{itn}}\right)$,

Where:

$\mathrm{W}_{\mathrm{it}}$ is CEO i's wealth in period $\mathrm{t}$,

$E\left(W_{i t}\right)$ is the expected value of CEO i's wealth in period $t$

$\rho_{\mathrm{i}}$ is the CEO's measure of absolute risk aversion

$\sigma_{W_{i t}}^{2}$ is the variance of the CEO's wealth in period t.

In this model, the CEO chooses effort levels on each task to maximize utility. There are n first order conditions:

$$
\mathrm{a}_{\mathrm{itj}}=\mathrm{b}_{\mathrm{i}} \gamma_{\mathrm{j}}\left(\mathrm{V}_{\mathrm{i} . \mathrm{l}}\right) \forall \mathrm{j}=\{1, .2, \ldots \mathrm{n}\}
$$

In this model, the CEO's effort decision on each task depends on the strength of the payfor-performance relation $\left(b_{i}\right)$, and on the marginal product of his effort on this task, $\gamma_{j}$. 
As in Section 2, the optimal $b_{i}$ involves the trading off incentives and risk. This model yields the following expression for the optimal slope for the compensation scheme:

$$
\mathrm{b}_{\mathrm{i}}^{*}=\frac{\sum_{j=1}^{n} \gamma_{i j}^{2}}{\sum_{j=1}^{n} \gamma_{i j}^{2}+2 \rho_{i} \sigma_{i}^{2}} .
$$

In the multi-tasking model, instead of $\mathrm{b}^{*}$ being a function of the marginal product of effort, it is a function of the marginal products of effort on each task. The more tasks that a CEO performs, and the more that each task affects firm value, the higher will be the optimal $b$. The "importance" of CEO actions relative to the randomness in firm value is now measured by the sum of squared marginal products.

With this model in mind, we can now reinterpret the results in Section IV. Nothing in the estimation procedure nor the reporting of the results need change: only the interpretation of the marginal product. Now, instead of estimating the relationship between size and $\gamma$, we are estimating the relationship between size and the term that replaced $\gamma$ in the numerator and denominator of Equation (5): $\sqrt{\sum_{j=1}^{n} \gamma_{i j}^{2}}$.

This multi-task model yields an interesting new set of predictions about how CEO effort will vary across different types of tasks in firms of different sizes. Note that, since the firm can choose only one $b^{*}$, the CEO's effort is allocated across tasks according to the marginal product of effort on that task (see Equation 4). This implies that CEOs of large firms, with optimally small b's, will tend to devote little attention to tasks whose marginal products do not scale with firm size compared to CEOs of small firms. Symmetrically, for those tasks whose marginal product grows proportionally with firm size, CEO effort in large firms will be much greater than that for CEOs of small firms. An example will help to illustrate.

Consider a simplification of the above model with two only two tasks-one that does not scale with firm size, and one that scales proportionally. There are two firms, one with market value of $\$ 100 \mathrm{M}$, the other with market value of $\$ 10 \mathrm{~B}$. According to our estimates in Section IV, $\sqrt{\Sigma \gamma_{\mathrm{j}}^{2}}$ should be about 40 times larger in the large firm, while $\mathrm{b}^{*}$ should be about 50 times smaller. With these estimates in mind, we make some assumptions about 
the marginal products of effort on the two tasks in the two firms, and calculate the CEO's effort choices in each firm. Our assumptions and simulation results are shown in Table 8.

\section{Table 8}

Simulation of effort choices across two tasks in firms of different sizes

\begin{tabular}{|c|c|c|}
\hline & Firm 1 & Firm 2 \\
\hline Firm Size & $\$ 100 \mathrm{M}$ & $\$ 10 B$ \\
\hline $\begin{array}{l}\text { Marginal Product on task } 1 \text { (doesn't scale } \\
\text { with firm size) }\end{array}$ & 1 & 1 \\
\hline $\begin{array}{l}\text { Marginal Product on task } 2 \text { (scales with } \\
\text { firm size) }\end{array}$ & .43 & 43 \\
\hline$\sqrt{\sum \gamma_{\mathrm{j}}^{2}}$ & 1.09 & $43.64(=1.09 * 40)$ \\
\hline $1000 \times b^{*}$ & 10 & $.2(=10 \div 50)$ \\
\hline Effort on task 1 (non-scaling task) & 10 & .2 \\
\hline Effort of task 2 (scaling task) & 4.3 & 8.6 \\
\hline$b * \sqrt{\sum \gamma_{j}^{2}}$ (effort intensity) & 10.9 & 8.7 \\
\hline
\end{tabular}

Note that, in the small firm, relative CEO effort is higher on the tasks that do not scale, while relative $\mathrm{CEO}$ effort in the large firm is greater for the tasks that do. This suggests that CEOs of large firms (relative to CEOs of small firms) will spend more of their time worrying about activities that have system-wide effects, and will spend less time worrying about those that do not. Similarly, CEOs of small firms will "sweat the details" more than the CEOs of large firms, and will expend relatively less effort on tasks that have more wide-ranging effects.

Firm size, control, and bureaucracy

This multi-task model also makes predictions about how large and small firms will differ in their design of management control systems, and about the optimality of a certain amount of bureaucratic "red tape" in larger firms.

Consider the relative magnitude of the agency problem for different tasks faced by large firms. For tasks whose marginal products scale with firm size, the low $b^{*}$ in the large firm will not be too great a problem: the high margin on the CEO's effort for these tasks will 
keep him attentive to this sort of activity. The CEO understands that if the development of a new corporate strategy raises the value of the firm by a small percentage, this represents a large amount of value creation, and therefore, a large wealth increase to the CEO (even with a small $b^{*}$ ). However, for tasks whose marginal products do not scale (such as perquisite consumption) with firm size, the very low $b^{*}$ in the large firms will induce significant agency costs. A cost of a corporate jet is not very great to a CEO who owns 0.2 percent of the firm.

In large firms, with low (but optimal) b's, boards will find it worthwhile to design control systems that monitor certain types of activities by CEOs (i.e. perquisite purchases) very carefully. Such systems are likely to filter down throughout the organization, appearing in the form of spending sign-offs, capital and operating budgeting systems, and other forms of red tape. Such systems will thus tend to be much more prevalent in large firms than in small ones. In this sense, bureaucracy increases optimally with firm size and is a necessary cost of being large. Monetary incentives designed to tie an executive's wealth to firm value simply will not solve the problem of inefficient perquisite consumption in large firms.

\section{Conclusion}

Both the theory and practice of executive pay are hampered by disagreement and confusion over the appropriate measure of CEO incentives. We show that this confusion, shared by academics and practitioners alike, derives from hidden assumptions about the nature of $\mathrm{CEO}$ actions and their effects on the value of their firms. These hidden assumptions become confounding when one attempts to measure "incentive strength" in firms of dramatically different sizes.

This paper attempts to clarify and answer questions about incentive strength in firms of very different sizes. Specifically, we ask: who has better incentives, the CEO of a large firm with a tiny fractional ownership but an equity stake worth tens of millions of dollars, or the CEO of a small firm who owns a significant share of company stock, but whose stake is worth much less?

Our theoretical results show that the answer to this question depends on how CEO actions affect firm value. If CEO actions have constant dollar effects across firms of different sizes, then a CEO's "percent owned" is the appropriate measure of incentives. If, on the other hand, CEO actions affect percentage returns on firm value, then the value of the CEO's 
"equity stake" is the correct measure of CEO incentive strength. We show that the critical parameter in establishing the relevance of different measures of incentives is the elasticity of the marginal product of CEO effort with respect to firm size. One of two polar case assumptions about the magnitude of this elasticity (zero - the marginal product is invariant with firm size; and one-the marginal product of effort scales proportionally with firm size) is implicit in most analyses of CEO pay and incentives.

Our empirical results indicates that neither polar case assumption is correct. We estimate that the elasticity of CEO marginal product with respect to firm size is roughly 0.4 . Thus CEO marginal products rise strongly, but not proportionally with firm size. One implication of this finding is that CEO incentives do not fall dramatically with firm size. Indeed, we estimate the CEO incentives are roughly constant or slightly declining as firm size increases.

Several conclusions emerge from these findings. First, it is useful to distinguish between pay-to-performance and what might be called "pay-to-effort" measures of incentive strength. Doing so highlights the importance of cross-sectional variation in CEO marginal products, and avoids confusion about the interpretation of pay sensitivity estimates. Second, the appropriate specification for estimating both pay sensitivity and incentive strength in cross-sectional data must account for these difference in CEO marginal products across the sample. While we have estimated these differences for firms of different sizes, and begun to do so for firms in different industries, one could imagine extending this methodology to investigate differences in managerial marginal products for firms with different capital intensities, with different levels of diversification, ${ }^{16}$ or with different organizational structures.

We also show that estimating the overall level of pay sensitivity for a CEO obscures an important point about CEO incentives for different types of activities. Since large firms (optimally) have much smaller b's, the incentives provided to executives for activities with relatively small dollar effects (such as perquisite consumption) will be weak. CEOs of large firms will thus be inclined to overspend on these types of activities, relative to CEOs of smaller firms. This does not imply, however, that the CEOs of larger firms face incentives that are weaker across-the-board. Indeed, since the dollar effects of their "system-wide"

\footnotetext{
16 Shephard and Rose (1997) find evidence that CEOs of more highly diversified firms have higher ability.
} 
activities can be so enormous, they will tend to exert more effort on these types of activities than CEOs of smaller firms.

Understanding top management incentives, and making sense of the welter of empirical results that exist in the literature, requires both a more flexible model of CEO production and a less rigid view of the determinants of CEO pay. The models and results in this paper are, we hope, a step in this direction. 


\section{References}

Aggarwal, Rajesh and Andrew A. Samwick, "The Other Side of the Tradeoff: The Impact of Risk on Executive Compensation," NBER working paper 6634, July 1998, forthcoming in the Journal of Political Economy.

Cuzick, J.,"A Wilcoxen-Type Test For Trend," Statistics in Medicine, Vol. 4, pp. 87-90, 1985.

Garen, John E., "Executive Compensation and Principal-Agent Theory," Journal of Political Economy, 102, no. 6, 1994.

Gibbons, Robert and Kevin J. Murphy, "Relative Performance Evaluation for Chief Executive Officers,” Industrial and Labor Relations Review, February 1990.

Hall, Brian J., "The Pay to Performance Incentives Created by Executive Stock Options," NBER working paper 6674, August 1998.

Hall, Brian J. and Jeffrey B. Liebman, "Are CEOs Really Paid Like Bureaucrats?" Quarterly Journal of Economics, Vol. CXII, Issue 3, pp. 653-691, August, 1998.

Haubrich, Joseph G., "Risk Aversion, Performance Pay and the Principal-Agent Problem," Journal of Political Economy, 1994.

Holmstrom, Bengt, "Comments," in Contract Economics, edited by Werin, Lars and Hans Wijkander, Blackwell, pp. 211-??, 1992

Jensen, Michael C. and William M. Meckling, "Theory of the Firm: Managerial Behavior, Agency Costs and Ownership Structure," Journal of Financial Economics, October 1976.

Jensen, Michael C. and Kevin J. Murphy, "Performance Pay and Top-Management Incentives," Journal of Political Economy, 1990b. 
Joskow, Paul and Nancy L. Rose and Andrea Shepard, "Regulatory Constraints on CEO Compensation," Brookings Papers on Economic Activity - Microeconomics 1, 1993.

Joskow, Paul L. and Nancy L. Rose, "CEO Pay and Firm Performance: Dynamics, Asymmetries, and Alternative Performance Measures," NBER working paper 4976, December 1994.

Murphy, Kevin J. ,"Corporate Performance and Managerial Remuneration: An Empirical Analysis," Journal of Accounting and Economics, April 1985.

Murphy, Kevin J., "Executive Compensation," forthcoming in O. Ashenfelter and D. Card, editors, Handbook of Labor Economics, Vol. 3, North Holland, 1998.

Palia, Darius, “The Impact of Regulation on CEO Labor Markets," Draft, May 1998.

Rosen, Sherwin, "Contracts and the Market for Executives," in Contract Economics, edited by Werin, Lars and Hans Wijkander, Blackwell, pp. 181-211, 1992.

Rose, Nancy and Andrea Shepard, "Firm Diversification and CEO Compensation: Managerial Ability and Executive Entrenchment," Rand Journal of Economics, Vol 28 No. 3, Autumn 1997. Pp. 489-514.

Schaefer, Scott, "The Dependence of Pay-Performance Sensitivity on the Size of the Firm," The Review of Economics and Statistics, 1998.

Wilcoxen, F. "Individual Comparisons by Ranking Method," Biometrics, Vol. 1, pp 8083, 1945. 